\title{
Extravascular lung water index as an indicator of lung injury in septic patients
}

BY ŽELJKO DRVAR, VIŠNJA MAJERIĆ KOGLER, DINKO TONKOVIĆ, MIRJANA MIRIĆ, MARIO PAVLEK, MLADEN PERIĆ

\section{Abstract}

Introduction. Transpulmonary thermodilution using PiCCO (Pulse-induced Contour Cardiac Output) is a standard minimally invasive method used for haemodynamic monitoring. Objectives. The goal of this paper is to examine the correlation and dynamics of the ExtraVascular Lung Water Index (EVLWI) as an indicator of acute lung injury in septic patients who underwent major abdominal surgery. Two groups of patients were selected: the ones with ALI (Acute Lung Injury): ALI patient group, and the ones without ALI: non-ALI patient group. A correlation between EVLWI and other haemodynamic and respiratory data in both groups were analyzed.

Materials and methods. The study included 48 patients. Throughout the seven-day period EVLWI, GEDVI (Global End-Diastolic Volume Index), ITBVI (IntraThoracic Blood Volume Index), CI (Cardiac Index), SVRI (Systemic Vascular Resistance Index) were measured in both groups using PiCCO monitoring over 8-hour intervals as well as heart rate, mean arterial pressure, serum albumin concentration, $\mathrm{PaCO}_{2}$ (arterial partial pressure of carbon dioxide), $\mathrm{PaO} 2$ (arterial partial pressure of oxygen), $\mathrm{PaO} 2 / \mathrm{FiO}_{2}$ (arterial partial pressure of oxygen/fraction of inspired oxygen) ratio, lung compliance, lung resistance and $\mathrm{ScvO} 2$ (central venous oxygen saturation). All patients were analgosedated, intubated, mechanically ventilated, in sinus cardiac rhythm. Circulatory unstable patients had vasoactive support and Sequential Organ Failure Assessment (SOFA) scores calculated. Ventilator settings and dosage of vasoactive drugs were kept 
constant during the study.

Results. EVLWI was significantly higher in ALI patients group compared to nonALI patients group. In patients with ALI group 11/22 patients died (50\%), in the non-ALI patients group 6/26 patients died (23\%). EVLWI was significantly higher in patients that died compared to ones who survived.

Conclusion. EVLWI is a good indicator of early acute lung injury in surgical patients with sepsis.

Key words: extravascular lung water index, acute lung injury, PiCCO monitoring, sepsis

\section{Introduction}

It is possible to measure EVLWI (ExtraVascular Lung Water Index) by TPTD (TransPulmonary ThermoDilution) technique using PiCGO (Pulse-induced Contour Cardiac Output) monitoring. It is a standard minimally invasive method used for continuous monitoring of haemodynamic and volumetric parameters combining TPTD method and pulse curve analysis. $(1,2)$

EVLWI is defined as the difference between ITTV (IntraThoracic Thermal Volume), which is measured by transpulmonary thermodilution, and ITBV (IntraThoracic Blood Volume), see formula 1. By indexing the retreived data according to body mass we can extrapolate EVLWI, see formula 2. As it is not possible to get ITBV by transpulmonary thermodilution, instead an indirect indicator is measured, that is GEDV (Global End-Diastolic Volume), see formula 3. EVLWI is indicative of the volume in interstitial lung tissue and intraalveolar space. $(3,4)$ Indirect acute lung injury is a common consequence of sepsis. According to the literature, Acute Lung Injury (ALI) occurs in $37-41 \%$ of all sepsis patients. Depending on the diagnostic criteria, age groups and therapeutic protocols, the death rate is $29-42 \%$. (5-12) ALI is characterized by hypoxemia, non-cardiogenic lung oedema, poor lung compliance and increased alveolar capillary permeability. (13)

Increased alveolar capillary permeability is a result of bacterial endotoxins, migration and adherence of polymorphonuclear leukocytes as well as a number of inflammatory factors: neutrophil elastase, colagenase A and B, protease and nitric oxide. Other pro-inflammatory factors transmit the systemic inflammatory response to the lungs: TNF- $\alpha$ (tumour necrosis factor $\alpha$ ), IL-1 $\beta$ (interleukin $1 \beta$ ), IL- 
6 (interleukin 6), IL-8 (interleukin 8), leukotriene and cyclooxygenase pathways without fibrinolysis, the C5a complement system, along with numerous chemokines and cytokines. (14)

Along with the aforementioned, the intensity of alveolar injury is dependent on the activity of thrombin, oxygen radicals, proteolytic enzymes and adhesion molecules. As a result surfactant formation is insufficient and its action is inadequate. Consequently, destruction of capillary endothelium and alveolar epithelium causes increased vascular permeability and quickly results in fluid collection in the interstitial space and in alveoli. (14)

The EVLWI reference range in healthy adults is $3.0-7.0 \mathrm{ml} / \mathrm{kg}$. EVLWI values above $10 \mathrm{ml} / \mathrm{kg}$ indicate development of pulmonary oedema and correlate with morbidity and mortality. A 100\% increase in EVLWI values are not clinically evident on chest $\mathrm{x}$-rays, while those of a $200-300 \%$ increase are correlated to significant hypoxemia. (15)

The goal of this paper is to examine the correlation and dynamics of the EVLWI as an indicator of acute lung injury in septic patients who have undergone major abdominal surgery.

\section{Materials and methods}

This prospective observational study was conducted from May 2009 until October 2011, at the Department of Anaesthesiology, Reanimatology and Intensive care at the University Hospital of Zagreb. It included 48 septic patients who had undergone major abdominal surgery. Of the 48 patients, 25 were male aged 47 $(\mathrm{SD}=8)$ and 23 were female aged $43(\mathrm{SD}=7)$. They were divided into two groups. The first consisted of 22 patients who had ALI (ALI patients group), the second group, consisted of 26 patients, who were without ALI (non-ALI patients group). All of the participants had signed informed consent.

Diagnosis of both sepsis and ALI was based upon internationally defined criteria, clinical signs and symptoms, as well as laboratory results. (16-20)

Exclusion criteria are listed in table 1.

Upon admission to the intensive care unit, post-operatively, all of the patients had endotracheal tubes and were mechanically ventilated. They were all 
analgosedated with midazolam (0.08-0.2mg/kg/h) and sufentanil (0.3-0.5 $\mu \mathrm{g} / \mathrm{kg})$. Both drugs were applied intravenously by a syringe pump system.

Patients who were haemodynamically unstable (mean arterial pressure < $60 \mathrm{mmHg}$ ) were given vasoactive drugs (norepinephrine $0.6-1.8 \mu \mathrm{g} / \mathrm{kg} / \mathrm{min}$ ), and had their SOFA (Sequential Organ Failure Assessment) score calculated.

The ventilation mode was BIPAP (BiPhasic Positive Airway Pressure) and was set to $\mathrm{FiO}_{2}$ (fraction of inspired oxygen) $0.4-0.8$, respiratory rate of 12-18/min, Phigh (pressure high) 15-25cmH2O, Plow (pressure low) 5-8cmH2O, Thigh (time high) 25s, Tlow (time low) 0.5-1.os. All patients had a dual-lumen central venous catheter (Arrow International, $7 \mathrm{~F}, 20 \mathrm{~cm}$, Athlore, Ireland) placed in the internal jugular vein. Each patient had a chest x-ray done in order to confirm that the catheter was in place. Next, an intraarterial PiCCO catheter (Pulsiocath PV2014L16N, 4F) was placed into the femoral artery using Seldinger's method. Primary monitor used was Dräger Infinity Delta XL, Germany, with secondary input from PiCCO Dräger Infinity R PiCCO Smart Pod TM.

All of the measured variables, EVLWI, GEDVI (Global End-Diastolic Volume Index), ITBVI, CI (Cardiac Index) and SVRI (Systemic Vascular Resistance Index) were taken in both study groups using PiCCO in the same 8-hour intervals, three times a day throughout the study.

Each measurement was done using a thermodilution indicator, $15 \mathrm{ml}$ of cold $(<8 \% \mathrm{C}) 5 \%$ glucose solution, which was injected through the central venous catheter. The final value was the mean of three consecutive measurements, each taken within 5-minute intervals. PiCCO monitoring was used in both study groups within a seven-day time period until they achieved optimal haemodynamic and TPTD values. During this time period HR (Heart Rate), MAP (Mean Arterial Pressure), serum albumin concentration (as an indirect indicator of oncotic pressure within vascular system), $\mathrm{PaCO} 2$ (arterial partial pressure of carbon dioxide), $\mathrm{PaO}_{2}$ (arterial partial pressure of oxygen), $\mathrm{PaO} 2 / \mathrm{FiO} 2$ ratio (arterial partial pressure of oxygen/fraction of inspired oxygen), lung compliance and resistance, $\mathrm{ScvO} 2$ (central venous oxygen saturation) were all regulary measured.

Both study groups had chest x-rays, EGGs and transthoracic heart ultrasound (Siemens $\mathrm{P} 4-2$ probe) done in order to measure their left ventricular ejection fraction and diastolic heart dysfunction.

Both groups of patients were given crystalloids $(30 \mathrm{ml} / \mathrm{kg})$ up to the point at which 
their optimal preload was achieved (MAP $>60 \mathrm{mmHg}$, EVLWI $<7 \mathrm{ml} / \mathrm{kg}$, ITBVI $850-$ $1000 \mathrm{ml} / \mathrm{m} 2$, GEDVI 680-80oml $/ \mathrm{m} 2$ ). Patients with haemoglobin concentration $<7 \mathrm{Og} / \mathrm{l}$ and/or $\mathrm{CI} \leq 2.5 \mathrm{l} / \mathrm{min} / \mathrm{m} 2$ were given packed red cell transfusion.

All of the data measured or calculated was statistically processed using the independent t-test, along with ANOVA (ANalysis Of VAriance) applied for repeating measurements. Values of $\mathrm{p}<0.05$ were considered statistically significant.

\section{Results}

The study included 48 septic patients who had undergone major abdominal surgery. Of those, 22 had ALI and 26 did not. There were 14 male and 8 female patients in ALI group versus 11 male and 15 female patients in non-ALI group. Table 2 displays the results according to age, APACHE II (Acute Physiology and Chronic Health Evaluation II) score and SOFA score in ALI and non-ALI group. Patients with positive haemocultures received antibiotics according to the antibiogram (table 3). Microorganisms isolated from bronchoalveolar lavage samples in patients with ALI group are displayed in table 4.

EVLWI was markedly increased in the ALI patient group between the 3rd and 7 th day. Also, a statistically significant difference in EVLWI values was found between the two groups within the 1st and 7 th day (table 5). Furthermore, there was an evident positive growth trend of EVLWI with each passing day (table 5).

Figure 1 depicts the trends and differences of EVLWI in the two groups over a period of seven days. There is a discrepancy between the median of EVLWI in the two groups from 4 th to 7 th day. That is, the EVLWI in the non-ALI group of patients reaches a plateau, while in the ALI group it continues to rise.

Figure 2 depicts AUROC (Area Under Receiver Operating Characteristic) curve for EVLWI (0.943; 95\% confidence interval 0.849-0.987) with $\mathrm{p}<0.001$.

Optimal discrimination threshold between the groups was 14\% for EVLWI (sensitivity $72.2 \%$, specificity $97.5 \%$ ) which indicates that this diagnostic method is efficient.

There was also a statistically significant difference throughout the rest of the values measured in both groups: GEDVI, ITBVI, SVRI and GVP. Mean values of 
GEDVI as well as ITBVI in ALI group of patients were higher than reference values (table 6). CI values did not show a statistically significant difference between the two groups (table 6).

In the ALI patient group, there was a sharp rise in $\mathrm{PaCO} 2$ from the 3 rd day, while the non-ALI patient group showed a trend towards a decrease in $\mathrm{PaCO} 2$ from the 1st day onwards (table 5, figure 3). On the other hand, the measured difference in $\mathrm{PaO}_{2}$ in both patient groups showed a constant drop in $\mathrm{PaO}_{2}$ in the ALI patient group during a week-long observation that was greater than the decrease in $\mathrm{PaO}_{2}$ in the non-ALI patient group (table 5, figure 4). Albumin values were also tracked during the seven-day period. The results show that serum albumin concentration in the non-ALI patient group was greater in comparison to ALI patient group (table 5, figure 5). Patients with ALI had increased EVLWI values and reduced serum albumin concentrations.

The following lung function indices were monitored: $\mathrm{PaO} 2 / \mathrm{FiO} 2$ ratio, compliance, lung resistance and LIS (Lung Injury Score). The ALI patient group had a significantly higher resistance of the respiratory system and reduced compliance and $\mathrm{PaO} 2 / \mathrm{FiO}_{2}$ ratio in comparison to non-ALI patient group (table 7).

Total seven-day mortality in both research groups was $17 / 48$ patients (35\%). In the ALI patient group 11/22 patients died (50\%), while 6/26 (23\%) patients died in the non-ALI patient group. Measured EVLWI values on the 7 th day of monitoring were significantly increased in the group of deceased patients in comparison to those who survived: $16.5 \mathrm{ml} / \mathrm{kg}$ vs $12.4 \mathrm{ml} / \mathrm{kg}$ (figure 6).

\section{Discussion}

The results of this research study show that the EVLWI can be used in the assessment of the appearance and dynamics of acute lung injury in surgical patients with sepsis.

This is shown in the significantly higher EVLWI values in the ALI patient group when compared to the non-ALI patient group. EVLWI values in the ALI patient group were higher in patients who died than in those who survived. The initially measured EVLWI values in the ALI patient group were higher than in the non-ALI patient group, however it was still within the reference interval spread. A significant increase in measured EVLWI values in the ALI patient group began on 
the 3rd day and maximum values were attained on the 7 th day of measurement. Simultaneously with the increase in EVLWI, the ALI patient group presented a reduced serum albumin concentration. In the ALI patient group an increase in EVLWI resulted in significant lung function disorder, which could be seen through changes in relations between $\mathrm{PaO} 2 / \mathrm{FiO}_{2}$ ratio, lung compliance and lung resistance. The resulting hypoxemia was the result of hindered oxygen diffusion through the alveocapillary membrane and reduced lung compliance as well as increased lung resistance that stemmed from oedema and lung colapse.

The measured EVLWI values and the dynamics of the increase in the ALI patient group is in accordance with the stated goal of this research, as well as with the current knowledge on the subject. Recent data from the literature supports the effectiveness of EVLWI as an indicator for early detection of patients with ALI. (21, 22)

Cordemans et al. confirm the significance of the connection between EVLWI dynamics, intraabdominal hypertension, preload optimisation with fluid therapy in mechanically ventilated patients and poor treatment results in patients with ALI. (23) The meta-analysis of Zhongheng et al investigated EVLWI as an indicator of poor outcome in non-surgical patients with burns, sepsis and ALI. It included 11 studies carried out in 9 countries with a total of 670 patients between 1999 and 2010. EVLWI was significantly increased in the group of deceased patients in comparison to those who survived, with a median of $5.06 \mathrm{ml} / \mathrm{kg}$. (24) Our research showed a median of $6.6 \mathrm{ml} / \mathrm{kg}$.

The meta-regression analysis carried out by Eichhorn et al. researched the connection between EVLWI and GEDVI in the optimisation of preload in two different patient groups with sepsis, surgical and non-surgical. The surgical group consisted of patients after cardiac surgery, neurosurgery and vascular surgery. It analyzed a total of 138 studies with a total of 4682 patients published on PubMed with the keywords EVLWI, GEDVI and TPTD between 1990 and 2010. EVLWI and GEDVI were significantly higher in the patient group with sepsis after major surgery. (25)

Maharaj's overview consisted of research of PubMed using EVLWI, ALI and ARDS (Acute Respiratory Distress Syndrome) as keywords. It examined the usefulness of exact EVLWI quantification in diagnosis, treatment and prognosis of both ALI and ARDS. 
In conclusion, EVLWI is a useful indicator of clinical behaviour in mechanically ventilated patients, especially during PEEP (Positive End-Expiratory Pressure) titration, optimisation of volume therapy and poor patient outcome. (26)

The level of PEEP applied during mechanical ventilation can influence the measured EVLWI values, therefore the ventilator settings were constant throughout the research period. Of course, as in all research, this study has drawbacks: specifics of the observed population - surgical patients after laparotomy. Furthermore, the reliability of EVLWI measurements is reduced through vascular lung obstruction along with a change in the ventilation/perfusion ratio, including hypoxic lung vasoconstriction and a high PEEP level. An additional drawback is a small patient sample included in the research. Finally, the usefulness of applying TPTD technology in patients with heart shunts (recirculation of the indicator) is questionable. Both the first and the second group represented critically ill patients in need of haemodnaymic monitoring that is minimally invasive, with a goal of preventing possible complications.

The results of this research show that EVLWI can be useful for early detection of patients with ALI.

This is in accordance with expectations and assumptions built upon current literature. Insofar as all standards and prerequisites for the application of PiCCO monitors have been met, the obtained data on EVLWI make it a good indicator of the early onset of acute lung injury in patients with sepsis. EVLWI can also be an indicator of the effectiveness of the therapy in treating ALI, especially fluid therapy, mechanical ventilation strategies and treatment outcomes. However, for definitive confirmation of EVLWI value in an assessment of the onset of acute lung injury in patients with sepsis after major abdominal surgery, further research on a larger number of patients is necessary.

Formula 1.

EVLW=ITTV-ITBV

EVLW, ExtraVascular Lung Water; ITBV, IntraThoracic Blood Volume; ITTV, IntraThoracic Thermal Volume.

Formula 2.

$\mathrm{EVLWI}=\mathrm{EVLW} /($ predicted body weight) 
EVLW, ExtraVascular Lung Water; EVLWI, ExtraVascular Lung Water Index.

Formula 3.

$\mathrm{ITBV}=1.25 \times \mathrm{GEDV}-28.4$

GEDV, Global End-Diastolic Volume; ITBV, IntraThoracic Blood Volume.

Table 1. Exclusion criteria.

EXCLUSION CRITERIA

Coagulation disorders

Cardiomyopathy

Aortic valve insufficiency

Left ventricular ejection fraction $<45 \%$

Chronic obstructive lung disease

Children

Pregnant women

Patients who did not sign informed consent

Patients with contraindication for femoral artery puncture

Allergic diathesis

Disseminated malignancy

Table 2. Results according to age, APACHE II score and SOFA score in ALI patients group and non-ALI patients group. Data were statistically analyzed using independent t-test.

\begin{tabular}{llll} 
Property & Mean SD t P & \\
\hline Age & non-ALI 42.88.7 & 0.181 \\
& ALI $\quad 40.52 .1$ &
\end{tabular}

APACHE II scorenon-ALI24.22.0-4.3 <0.001

\begin{tabular}{|c|c|c|}
\hline & ALI & 02.7 \\
\hline \multirow[t]{2}{*}{ SOFA score } & \multicolumn{2}{|c|}{ non-ALI9.6 $0.8-18.3<0.001$} \\
\hline & ALI & 0.7 \\
\hline
\end{tabular}

ALI, Acute Lung Injury; APACHE II, Acute Physiology and Chronic Health Evaluation II score; SOFA score, Sequential Organ Failure Assessment score.

Table 3. Microorganisms isolated from haemocultures of ALI patients group and non-ALI patients group and their respective antibiotic therapy. 


\begin{tabular}{llll} 
Microorganism & $\begin{array}{l}\text { Number of positive } \\
\text { haemocultures }\end{array}$ & Antibiotic(s) & \\
\cline { 1 - 3 } & Patients with ALIn(\%) & $\begin{array}{l}\text { Patients without } \\
\text { ALIn(\%) }\end{array}$ & \\
\hline S. aureus & $2(6.9)$ & $3(15.8)$ & cloxacillin, \\
\hline S. aureus (MRSA) & $6(20.7)$ & $4(21.1)$ & clindamycin \\
\hline Coagulase negative & $4(13.8)$ & & teicoplanin, \\
staphylococcus & $8(27.6)$ & $2(10.5)$ & vancomycin \\
\hline $\begin{array}{l}\text { P. aeruginosa } \\
\text { K. pneumoniae ESBL }\end{array}$ & $5(17.2)$ & $6(31.6)$ & teicoplanin, \\
& & $2(10.5)$ & vancomycin \\
\hline A. baumanii & $4(13.8)$ & $2(10.5)$ & meropenem, colistin \\
\hline
\end{tabular}

ALI, Acute Lung Injury; ESBL, Extended Spectrum Beta Lactamase; MRSA, Methicillin Resistant Staphylococcus Aureus.

Table 4. Microorganisms isolated from bronchoalveolar lavage samples in ALI patient group.

\begin{tabular}{|c|c|}
\hline Microorganism & Number of positive culturesn(\%) \\
\hline S. aureus (MRSA) & $4(18.2)$ \\
\hline P. aeruginosa & $6(27.3)$ \\
\hline \multicolumn{2}{|c|}{ K. pneumoniae ESBL3(13.6) } \\
\hline C. albicans & $5(22.7)$ \\
\hline C. dubliniensis & $1(4.5)$ \\
\hline C. krusei & $3(13.6)$ \\
\hline
\end{tabular}

ALI, Acute Lung Injury; ESBL, Extended Spectrum Beta Lactamase; MRSA, Methicillin Resistant Staphylococcus Aureus

Table 5. Transpulmonary thermodilution and laboratories data in ALI patient group and non-ALI patient group during the seven-day period. Data were statistically analyzed using independent t-test.

\begin{tabular}{rccccc} 
Variable & \multicolumn{4}{c}{ Time ALIn=22non-ALIn=26t } & \\
\hline Mean & SD & MeanSD & & \\
\hline EVLWI(ml/kg)Day 17.09 & 0.29 & 5.27 & 0.3519 .37 & $<0.001$
\end{tabular}




\begin{tabular}{|c|c|c|c|c|c|}
\hline & Day 27.64 & 0.23 & 6.19 & 0.3516 .48 & $<0.001$ \\
\hline & Day 38.00 & 0.35 & 6.71 & 0.2515 .00 & $<0.001$ \\
\hline & Day 411.85 & 0.53 & 6.91 & 0.1745 .31 & $<0.001$ \\
\hline & Day 513.53 & 0.71 & 7.35 & 0.2541 .62 & $<0.001$ \\
\hline & Day 614.42 & 0.79 & 7.76 & 0.2440 .82 & $<0.001$ \\
\hline & Day 715.30 & 0.95 & 7.93 & 0.2538 .15 & $<0.001$ \\
\hline \multirow[t]{7}{*}{$\operatorname{Albumin}(\mathrm{g} / \mathrm{L})$} & Day 117.11 & 3.73 & 44.92 & $2.98-28.71$ & $<0.001$ \\
\hline & Day 215.88 & 3.16 & 44.09 & $92.65-33.67$ & $<0.001$ \\
\hline & Day 315.19 & 2.77 & 43.59 & $2.73-35.67$ & $<0.001$ \\
\hline & Day 414.64 & 2.55 & 43.36 & $2.71-37.56$ & $<0.001$ \\
\hline & Day 514.42 & 2.18 & 43.19 & $2.57-41.36$ & $<0.001$ \\
\hline & Day 614.46 & 2.14 & 42.82 & $2.61-40.60$ & $0<0.001$ \\
\hline & Day 714.61 & 2.27 & 42.48 & $2.66-38.62$ & $<0.001$ \\
\hline \multirow[t]{7}{*}{$\mathrm{PaCO} 2(\mathrm{kPa})$} & Day 15.37 & 0.50 & 5.95 & $0.50-4.01$ & $<0.001$ \\
\hline & Day 25.43 & 0.70 & 5.64 & $0.50-1.21$ & 0.231 \\
\hline & Day 35.56 & 0.80 & 5.47 & 0.500 .47 & 0.638 \\
\hline & Day 46.06 & 0.86 & 5.35 & 0.473 .62 & 0.001 \\
\hline & Day 56.54 & 1.03 & 5.16 & 0.545 .94 & $<0.001$ \\
\hline & Day 66.75 & 1.18 & 5.16 & 0.556 .17 & $<0.001$ \\
\hline & Day 77.05 & 1.42 & 5.11 & 0.476 .56 & $<0.001$ \\
\hline \multirow[t]{7}{*}{$\mathrm{PaO} 2(\mathrm{kPa})$} & Day 117.40 & 5.13 & 30.68 & $81.83-12.34$ & $<0.001$ \\
\hline & Day 215.58 & 5.03 & 27.64 & $2.78-10.50$ & $<0.001$ \\
\hline & Day 314.23 & 5.46 & 24.53 & $3.87-7.62$ & $<0.001$ \\
\hline & Day4 13.04 & 3.53 & 21.90 & $4.18-7.85$ & $<0.001$ \\
\hline & Day5 11.93 & 2.00 & 19.50 & $4.40-7.44$ & $<0.001$ \\
\hline & Day6 11.23 & 1.34 & 17.97 & $4.27-7.09$ & $<0.001$ \\
\hline & Day7 10.87 & 1.76 & 16.33 & $4.01-5.91$ & $<0.001$ \\
\hline
\end{tabular}

ALI, Acute Lung Injury; EVLWI, ExtraVascular Lung Water Index; P, significance level; $\mathrm{PaCO} 2$, arterial partial pressure od carbon dioxide; $\mathrm{PaO} 2$, arterial partial pressure of oxygen; $t$, $t$ score for independent t-test.

Table 6. Haemodynamic data in ALI patient group and non-ALI patient group during the seven-day period. Data were statistically analyzed using independent t-test. 


\begin{tabular}{|c|c|c|c|c|c|c|c|}
\hline \multicolumn{2}{|c|}{$\begin{array}{l}\text { Reference } 680-800 \\
\text { values }\end{array}$} & \multirow{2}{*}{$\begin{array}{l}850-1000 \\
697.0 \pm 55.1\end{array}$} & \multirow{2}{*}{$\begin{array}{l}3.0-5.0 \\
907.5 \pm 65.3\end{array}$} & \multirow{2}{*}{$\begin{array}{l}1700-2400 \\
4.2 \pm 0.4\end{array}$} & \multirow{2}{*}{$\begin{array}{l}65-75 \\
2050.0 \pm 185.8\end{array}$} & \multirow{2}{*}{$\begin{array}{l}0-8 \\
73.9 \pm 2.8\end{array}$} & \multirow[b]{2}{*}{$9.5 \pm 0.9$} \\
\hline $\begin{array}{l}\text { non- } \\
\text { ALIn=26 }\end{array}$ & Mean \pm SD & & & & & & \\
\hline \multirow[t]{14}{*}{$\mathrm{ALIn}=22$} & $\begin{array}{l}\text { Day } 1 \text { mean } \\
\pm \mathrm{SD}\end{array}$ & $947.0 \pm 214.0$ & $1087.0 \pm 245.8$ & $4.0 \pm 1.2$ & $1530.1 \pm 530.7$ & $72.6 \pm 6.3$ & $10.3 \pm 1.6$ \\
\hline & Test results* & $\mathrm{t}=5.7 \mathrm{p}<0.001$ & $\mathrm{t}=3.6 \mathrm{p}<0.001$ & $\mathrm{t}=-0.8 \mathrm{p}=0.428$ & \multicolumn{3}{|c|}{$\mathrm{t}=-4.7 \mathrm{p}<0.001 \mathrm{t}=-0.9 \mathrm{p}=0.347 \mathrm{t}=2.2 \mathrm{p}=0.035$} \\
\hline & $\begin{array}{l}\text { Day } 2 \text { mean } \\
\pm \mathrm{SD}\end{array}$ & $988.8 \pm 194.5$ & $1120.7 \pm 232.6$ & $4.2 \pm 1.1$ & $1497.1 \pm 423.1$ & $73.2 \pm 7.7$ & $10.1 \pm 1.5$ \\
\hline & Test results* & $\mathrm{t}=7.3 \mathrm{p}<0.001$ & $\mathrm{t}=4.5 \mathrm{p}<0.001$ & $\mathrm{t}=0.0 \mathrm{p}=0.999$ & \multicolumn{3}{|c|}{$\mathrm{t}=-0.6 \mathrm{p}<0.001 \mathrm{t}=-0.4 \mathrm{p}=0.668 \mathrm{t}=1.7 \mathrm{p}=0.094$} \\
\hline & $\begin{array}{l}\text { Day } 3 \text { mean } \\
\pm \mathrm{SD}\end{array}$ & $1026.3 \pm 179.4$ & $1165.7 \pm 222.1$ & $4.3 \pm 1.1$ & $1506.3 \pm 347.1$ & $73.6 \pm 7.4$ & $12.1 \pm 1.4$ \\
\hline & Test results* & $\mathrm{t}=8.9 \mathrm{p}<0.001$ & $\mathrm{t}=5.7 \mathrm{p}<0.001$ & $\mathrm{t}=0.4 \mathrm{p}=0.668$ & \multicolumn{3}{|c|}{$t=-6.9 p<0.001 t=-0.2 p=0.849 t=7.7 p<0.001$} \\
\hline & $\begin{array}{l}\text { Day } 4 \text { mean } \\
\pm \mathrm{SD}\end{array}$ & $1053.9 \pm 164.1$ & $1196.1 \pm 218.3$ & $4.4 \pm 1.2$ & $1469.4 \pm 325.2$ & $77.4 \pm 5.9$ & $11.8 \pm 1.4$ \\
\hline & Test results* & $\mathrm{t}=10.4 \mathrm{p}<0.001$ & $1 \mathrm{t}=6.4 \mathrm{p}<0.001$ & $1 \mathrm{t}=0.8 \mathrm{p}=0.427$ & \multicolumn{2}{|c|}{$\mathrm{t}=-7.7 \mathrm{p}<0.001 \mathrm{t}=2.6 \mathrm{p}=0.009$} & $\mathrm{t}=6.8 \mathrm{p}<0.001$ \\
\hline & $\begin{array}{l}\text { Day } 5 \text { mean } \\
\pm \mathrm{SD}\end{array}$ & $1081.1 \pm 164.7$ & $1213.8 \pm 218.5$ & $4.4 \pm 1.2$ & $1375.7 \pm 365.1$ & $77.2 \pm 5.5$ & $11.4 \pm 1.3$ \\
\hline & Test results* & $\mathrm{t}=11.2 \mathrm{p}<0.001$ & $\mathrm{t}=6.8 \mathrm{p}<0.001$ & $1 \mathrm{t}=0.8 \mathrm{p}=0.427$ & \multicolumn{2}{|c|}{$\mathrm{t}=-8.2 \mathrm{p}<0.001 \mathrm{t}=2.6 \mathrm{p}=0.010$} & $\mathrm{t}=5.9 \mathrm{p}<0.001$ \\
\hline & $\begin{array}{l}\text { Day } 6 \text { mean } \\
\pm \mathrm{SD}\end{array}$ & $1093.7 \pm 176.1$ & $1233.6 \pm 222.9$ & $4.4 \pm 1.3$ & $1323.0 \pm 443.3$ & $76.8 \pm 7.1$ & $11.6 \pm 1.6$ \\
\hline & Test results* & $\mathrm{t}=10.9 \mathrm{p}<0.001$ & $1 \mathrm{t}=7.1 \mathrm{p}<0.001$ & $\mathrm{t}=0.7 \mathrm{p}=0.460$ & \multicolumn{2}{|c|}{$\mathrm{t}=-7.6 \mathrm{p}<0.001 \mathrm{t}=1.9 \mathrm{p}=0.061$} & $\mathrm{t}=5.7 \mathrm{p}<0.001$ \\
\hline & $\begin{array}{l}\text { Day } 7 \text { mean } \\
\pm \mathrm{SD}\end{array}$ & $1068.8 \pm 159.7$ & $1181.8 \pm 186.4$ & $4.5 \pm 1.1$ & $1500.0 \pm 391.1$ & $72.2 \pm 8.8$ & $10.8 \pm 1.2$ \\
\hline & Test results* & $\mathrm{t}=11.3 \mathrm{p}<0.001$ & $\mathrm{t}=7.0 \mathrm{p}<0.001$ & $1 \mathrm{t}=1.3$ & \multicolumn{3}{|c|}{$\mathrm{t}=-6.4 \mathrm{p}<0.001 \mathrm{t}=-0.9 \mathrm{p}=0.356 \mathrm{t}=4.3 \mathrm{p}<0.001$} \\
\hline
\end{tabular}

ALI, Acute Lung Injury; CI, Cardiac Index; CVP, Central Venous Pressure; GEDVI, Global End-Diastolic Volume Index; ITBVI, IntraThoracic Blood Volume Index; ScvO2, central venous oxygen saturation; SVRI, Systemic Vascular Resistance Index.

*independent t-test results compared to non-ALI patients

Table 7. Lung function indicators expressed as a standard deviation in ALI patient group and non-ALI patient group. Data were statistically analyzed using independent t-test.

\begin{tabular}{ll} 
Variable & \multicolumn{3}{|l}{ ALIn=22non-ALIn=26t $\quad P$} \\
Mean SD & MeanSD
\end{tabular}




\begin{tabular}{lrlllll}
$\mathrm{PaO} 2 / \mathrm{FiO} 2$ & 19.33 & 0.75 & 42.77 & 1.16 & $-81.31<0.001$ \\
\hline Compliance $(\mathrm{ml} / \mathrm{cmH} 2 \mathrm{O}) 13.56$ & 0.62 & 22.19 & 1.43 & $-26.28<0.001$ \\
\hline Resistance $(\mathrm{cmH} 2 \mathrm{O} / \mathrm{L} / \mathrm{s})$ & 3.33 & 0.46 & 2.33 & 0.50 & 7.14 & $<0.001$ \\
\hline LIS score & 1.60 & 0.36 & & 0.00 & 0.0022 .88 & $<0.001$
\end{tabular}

ALI, Acute Lung Injury; LIS, Lung Injury severity Score; P, significance level; $\mathrm{PaO} 2 / \mathrm{FiO} 2$, arterial pressure of oxygen/fraction of inspired oxygen; SD, standard deviation; $t$, $t$ score for independent t-test.

Figure 1. EVLWI (ExtraVascular Lung Water Index) in ALI (Acute Lung Injury) patient group and non-ALI patient group during the seven-day period. Data were analyzed using independent t-test and ANOVA (ANalysis Of VAriance).

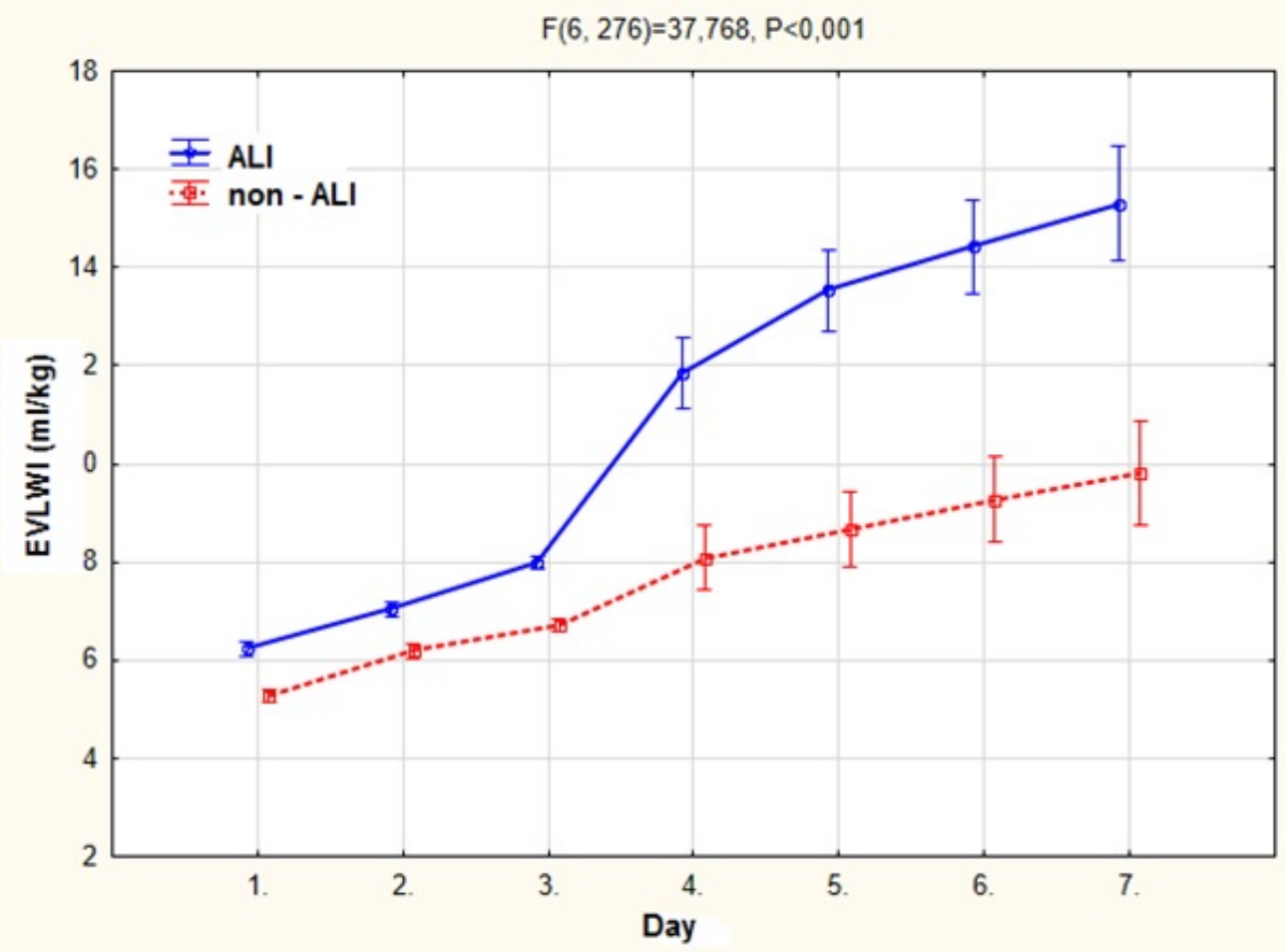

Figure 2. AUROC (Area Under Receiver Operating Characteristic) curve for EVLWI (ExtraVascular Lung Water Index); (o.943; 95\% confidence interval o.849-0.987) with $\mathrm{p}<0.001$. 


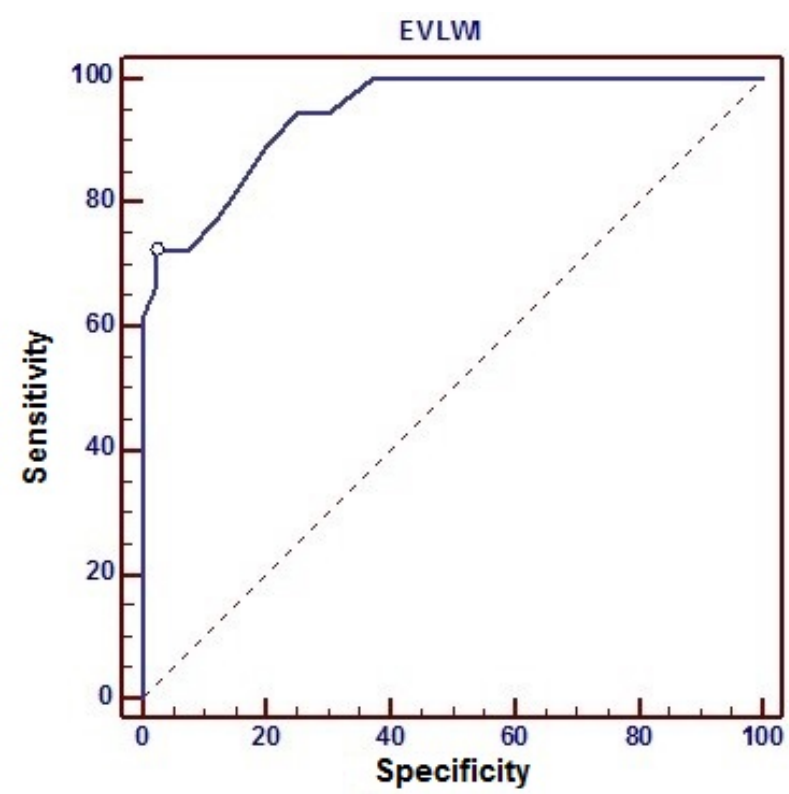

Figure 3. $\mathrm{PaCO} 2$ (arterial partial pressure of carbon dioxide) in ALI (Acute Lung Injury) patient group and non-ALI patient group during the seven-day period. Data were analyzed using independent t-test and ANOVA (ANalysis Of VAriance).

$F(6,276)=26,71, P<0,001$

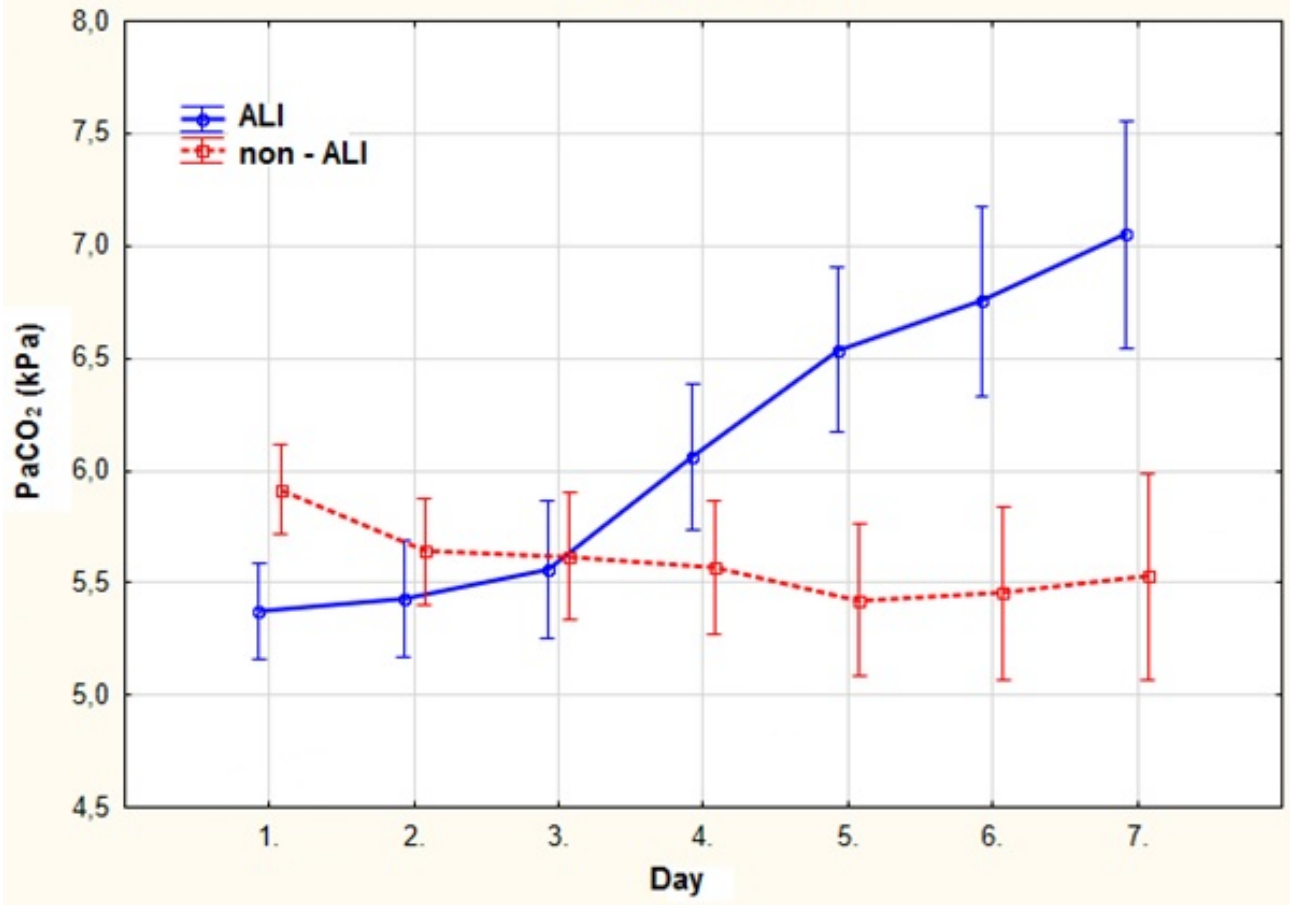

Figure 4. $\mathrm{PaO} 2$ (arterial partial pressure of oxygen) in ALI (Acute Lung Injury) patient group and non-ALI patient group during the seven-day period. Data were analyzed using independent t-test and ANOVA (ANalysis Of VAriance). 


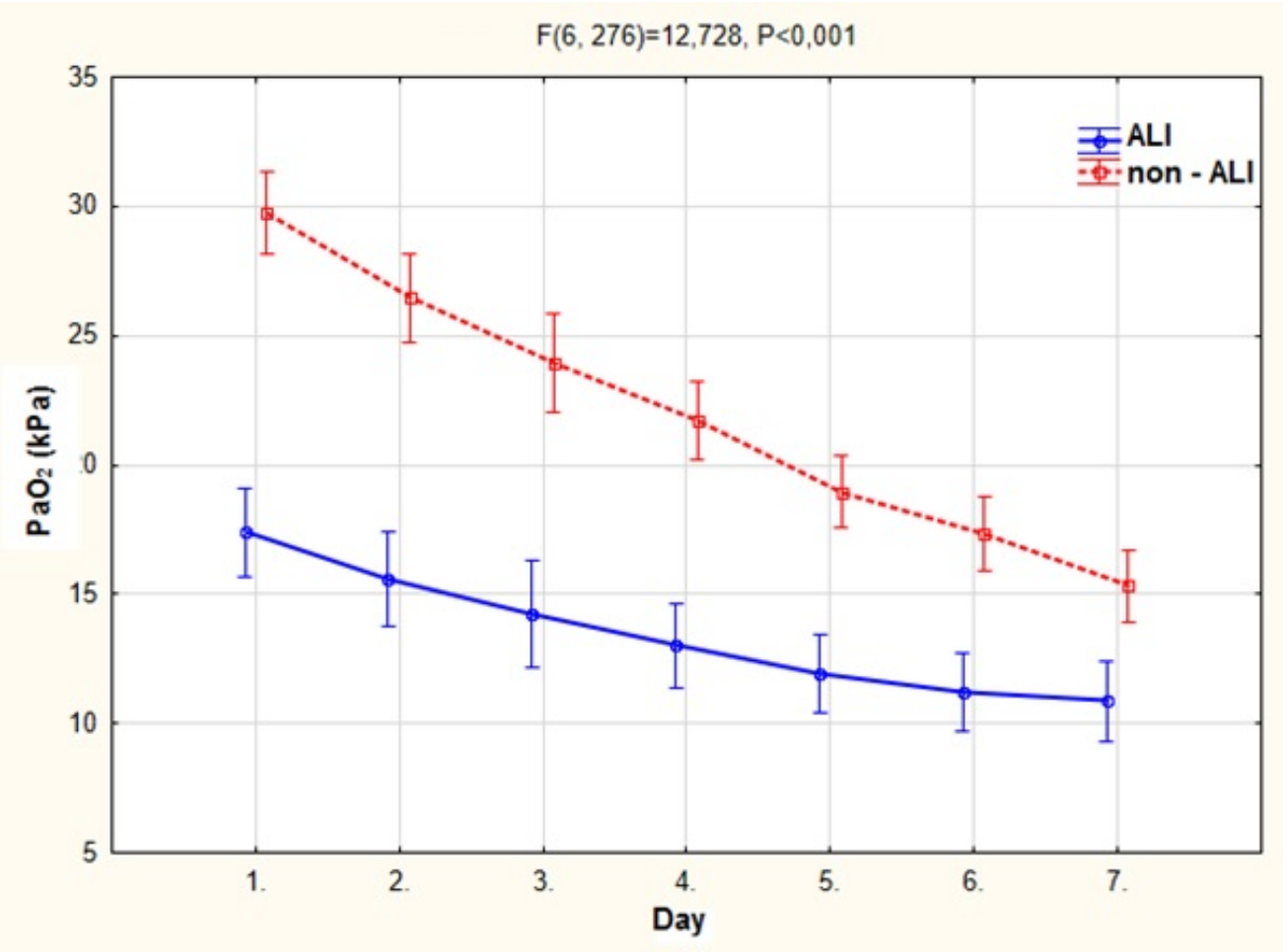

Figure 5. Serum albumin concentration in ALI (Acute Lung Injury) patient group and non-ALI patient group during the seven-day period. Data were analyzed using independent t-test and ANOVA (ANalysis Of VAriance). 


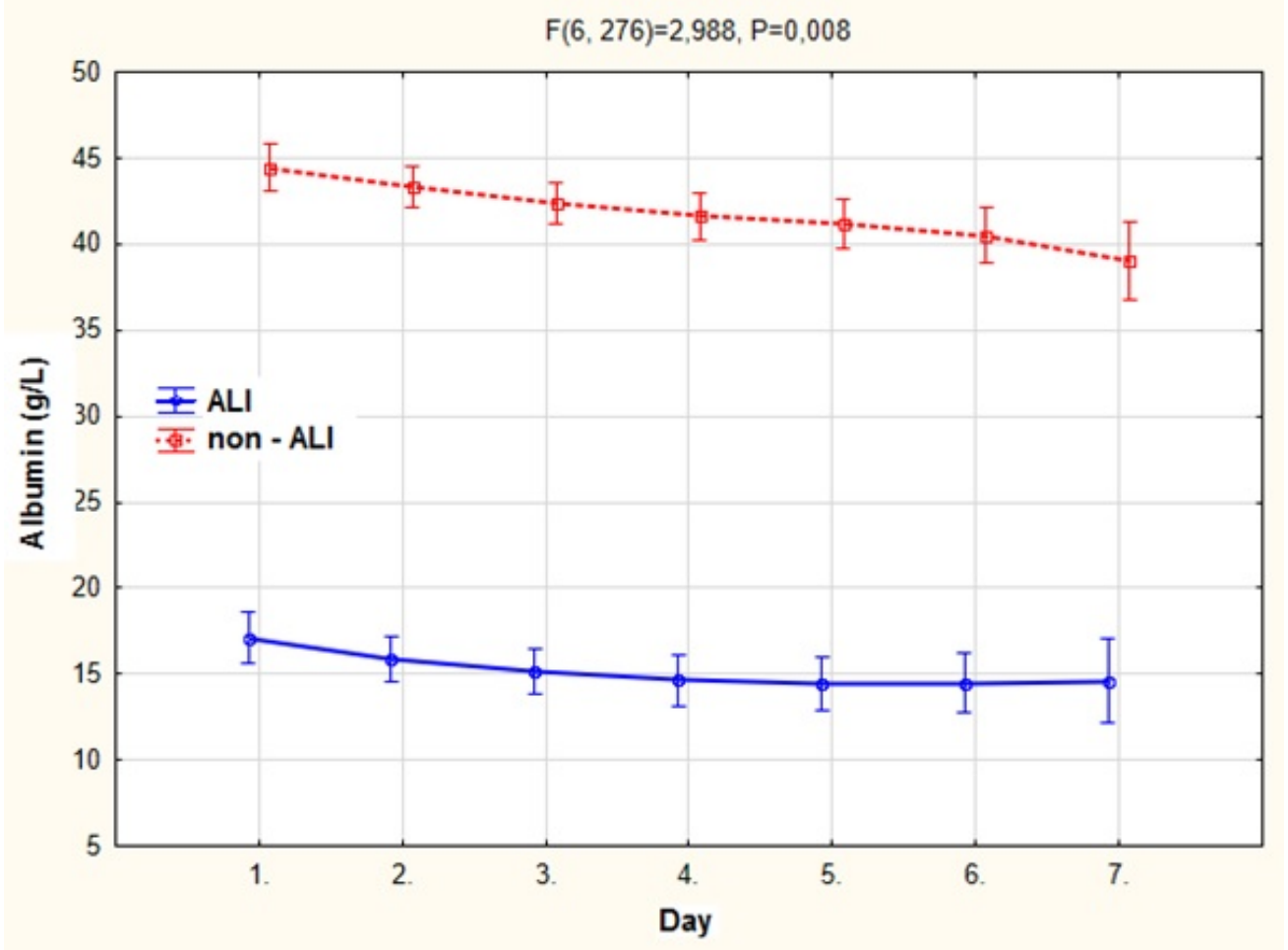

Figure 6. EVLWI (ExtraVascular Lung Water Index) in patients who survived and patients who did not survive sepsis after major abdominal surgery in this study. Data were analyzed using independent t-test and ANOVA (ANalysis Of VAriance).

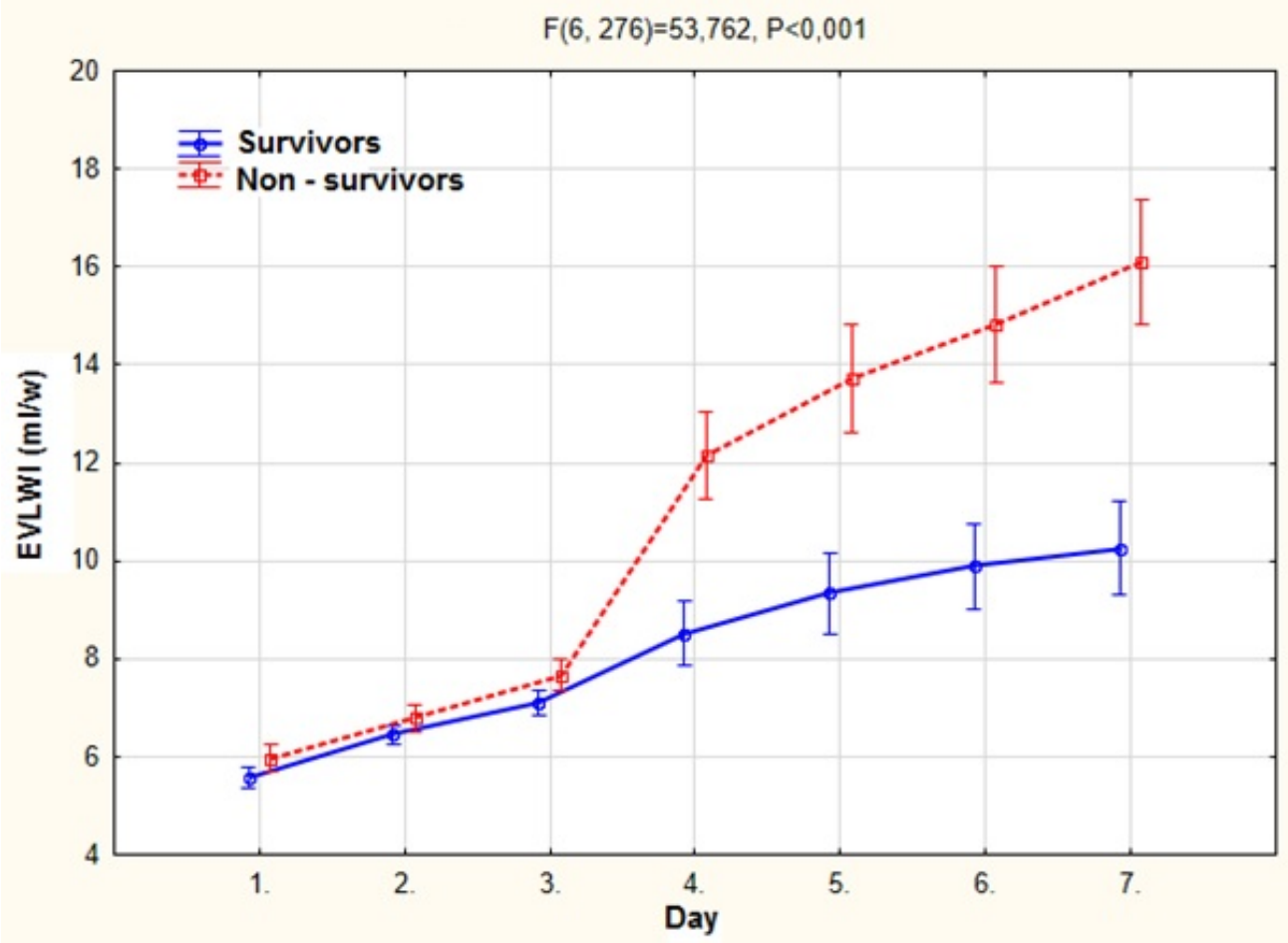




\section{References}

1. Chung FT, Lin SM, Lin SY, Lin HC. Impact of extravascular lung water index on outcomes of severe sepsis patients in medical intensive care unit. Respir Med 2008;102(7):956-61.

2. Craig TR, Duffy MJ, Shyamsundar M, McDowell C, McLaughlin B, Elborn JS, et al. Extravascular water indexed to predicted body weight is a novel predictor of intensive care unit mortality in patients with acute lung injury. Crit Care Med 2010;38:114-20.

3. Chew MS,Ihrman L, DuringJ, Bergenzaun L, Ersson A, Unden J, et al.

Extravascular lung water index improves the diagnostic accuracy of lung injury in patients with shock. Crit Care 2012;16:R1.

4. Vish M, Shanley PT. Acute Lung Injury and Acute Respiratory Distress Syndrome. In: Wheeler DS, Wong HR, Shanley TP, editors. The respiratory tract in pediatric critical illness and injury. London: Springer-Verlag; 2009. p. 49-67.

5. Ware LB, Matthay MA. The acute respiratory distress syndrome. N Engl J Med 2000;342(18):1334-49.

6. Piantadosi CA, Schwartz DA. The acute respiratory distress syndrome. Ann Intern Med 2004;141(6):460-70.

7. Martin GS, Eaton S, Mealer M, Moss M. Extravascular lung water in patients with severe sepsis: a prospective cohort study. Crit Care 2005;9:74-82.

8. Kuzkov V, Kirov M, Sovershaev A. Extravascular lung water deterimned with single transpulmonary thermodilution correlates with the severity of sepsisinduced acute lung injury. Crit Care Med 2006;122(6):1647-53.

9. Schmidt S, Westhoff TH, Hofmann C, Schaefer JH, Zidek W, Compton F, et al. Effect of the venous catheter site on transpulmonary thermodilution measurement variables. Crit Care Med 2007;35:783-6.

10. Monnet X, Anguel N, Osman D, Hamzaoui O, Richard C, Teboul JL. Assessing pulmonary permeability by transpulmonary thermodilution allows differentiation of hydrostatic pulmonary edema from ALI/ARDS. Int Care Med 2007;33(3):448-53.

11. Kumar A. Sepsis and septic shock. In: Gabrielli A, Layon AJ, Yu M, editors. Critical Care. Philadelphia: Lippincott \& Wilkins; 2009. p. 855-92.

12. Peters CW, Yu M, Sladen RN, Gabrielli A, Layon AJ. Acute lung injury and acute respiratory distress syndrome. In: Gabrielli A, Layon AJ, Yu M, editors. Critical Care. Philadelphia: Lippincott \& Wilkins; 2009. p. 2061-80.

13. Johnson ER, Matthay MA. Acute lung injury: epidemiology, pathogenesis and treatment. J Aerosol Med Pulm Drug Deliv 2010;23(4):234-52. 
14. Ware LB, Koyama T, Billheimer DD, Wu W, Bernard GR, Thompson BT, et al. Prognostic and pathogenetic value of combining clinical and biochemical indices in patients with acute lung injury. Chest 2010;137(2):288-96.

15. Fernandez-Mondjar E, Guerrero-Lopez F, Colomenero M. How important is the measurement of extravascular lung water? Crit Care 2007;13:79-83.

16. Dellinger P, Mitchell M, Rhodes A, Annane D, Gerlach H, Opal SM, et al. Surviving Sepsis Campaign: International Guidelines for Management of Severe Sepsis and Septic Shock. JAMA 2012;308(16):1641-50.

17. Levy MM, Dellinger P, Townsend SR, Linde-Zwirble WT, Marshall JC, Bion J, et al. Surviving sepsis campaign. Crit Care Med 2010;38(2):367-74.

18. Levy MM, Fink MP, Marshall JC, Abraham E, Angus D, Cook D, et al. 2001 SCGM/ESICM/ACCP/ATS/SIS International Sepsis Definition Cnoference. Crit Care Med 2003;31(4):1250-6.

19. Bernard GR, Srticas A, Gordon R, CarletJ, Dreyfuss D, Gattinoni L, et al.The American-European Consensus Conference on ARDS. AMJ Respir Crit Care Med 1998;157:1332-47.

20. Ranieri VM, Rubenfeled GD, Thompson BT, Ferguson ND, Caldwell E, Fan E, et al. Acute Respiratory Distress Syndrome: The Berlin Definition. JAMA 2012;307:252633.

21. Kushimoto S, Tomoyuki E, Satoshi Y, Sakamoto T, Ishikura H, Kitazawa Y, et al. Relationship between extravascular lung water and severity categories of acute respiratory distress syndrome by the Berlin Definition. Crit Care 2013;17(4):R132.

22. Perel A. Extravascular lung water and the pulmonary vascular permeability index may improve the definition of ARDS. Crit Care 2013;17:108.

23. Cordemans C, De Laet I, Van Regenmortel N, Schoonheydt K, Dits H, Huber W, et al. Fluid management in critically ill patients: the role of extravascular lung water, abdominal hypertension, capillary leak and fluid balance. Annals of Intensive Care 2012;2(1):S1.

24. Zhongheng Z, Balong L, Hongying N. Prognostic value of extravascular lung water index in critically ill patients: a systematice review of the literature.J Crit Care 2012;27(4):420.e1-8.

25. Eichhorn V, Goepfert MS, Eulenburg C, Malbrain M, Reuter DA. Comparison of values in critically ill patients for global end-diastolic volume and extravascular lung water measured by transcardiopulmonary thermodilution: A metaanalysis of the literature. Med Intensiva 2012;36(7):467-74.

26. Maharaj R. Extravascular lung water and acute lung injury. Cardiol Res Pract 2012;Article ID 407035. 
SIGNA VITAE 2015; 10(1): 74 - 92

Željko Drvar, Višnja Majerić Kogler, Dinko Tonković, Mirjana Mirić, Mario Pavlek, Mladen Perić

Department of Anaesthesiology, Reanimatology and Intensive Care, University Hospital Zagreb , Zagreb, Croatia Višnja Majerić Kogler, Mladen Perić

University of Zagreb School of Medicine, Zagreb, Croatia

Corresponding author

Željko Drvar

Department of Anaesthesiology, Reanimatology and Intensive care

University Hospital Zagreb

Kišpatićeva 12, 1000 Zagreb

Croatia

Phone: +3850989020241

E-mail: zeljko.drvar@email.t-com.hr 